Check for updates

Cite this: RSC Adv., 2018, 8, 38210

Received 15th September 2018

Accepted 1st November 2018

DOI: $10.1039 / c 8 r a 07680 d$

rsc.li/rsc-advances

\section{Interface conjugation enhances the interface adhesion performance of carbon fiber-reinforced phthalonitrile composites by $\pi-\pi$ stacking}

\author{
Changping Yin, ${ }^{\mathrm{b}}$ Liping Sheng, (D) *a Yudong Yang, ${ }^{a}$ Gengyuan Liang, ${ }^{\mathrm{b}}$ Suli Xing, ${ }^{\mathrm{b}}$ \\ Jingcheng Zeng ${ }^{\mathrm{b}}$ and Jiayu Xiao ${ }^{\mathrm{b}}$
}

\begin{abstract}
There has been little research focus on the interface problems of phthalonitrile (PN) resin and carbon fiber. However, interface performance is related to the overall mechanical properties of composites and is very important. This study focused on the interfacial performance and adhesion mechanism of a carbon fiber $\mathrm{C}_{\mathrm{f}} / \mathrm{PN}$ composite. Micro-composites of $\mathrm{C}_{\mathrm{f}} / \mathrm{PN}$ and $\mathrm{C}_{\mathrm{f}} /$ epoxy resins were prepared, and their interfacial shear strengths (IFSS) were tested by micro-droplet testing. The result showed that the IFSS of $C_{f} / P N$ was higher than that of $\mathrm{C}_{\mathrm{f}} /$ epoxy resin, indicating that the interfacial adhesion of the PN matrix composite must be more effective. To explain the obtained results, a number of tests, including SEM, SEM-EDS, FTIR, and TGA, were carried out. From the SEM analyses, cured PN polymer films were found on the surface of de-bonded carbon fibers. With the aid of SEM-EDS, the elements on the de-bonded carbon fiber surface of the $C_{f} / P N$ composite were detected in situ. An interesting synchronous relationship was observed in the IFSS and SEM-EDS results. Through the FTIR spectra, the chemical structures of the PN polymers were identified. From the detailed analyses and discussion in this work, the effective interfacial bond function in the $C_{f} / P N$ composite appears to be a complex result for all relative functions. The functional advantage of the PN composite may be the interface conjugation between the PN polymers and the graphene layer on the surface of the carbon fiber.
\end{abstract}

\section{Introduction}

The interface between matrix and fibers manipulates the reintroduction of stress into either component at a given damage site. Therefore, the interface is highly responsible for the micromechanical failures and the durability of composite materials..$^{1-5}$ Phthalonitrile (PN) resin is a high-performance matrix with excellent mechanical properties, high glass transition temperature, and flame-resistance properties. Recently, it has attracted more attention and has been applied in aviation, aerospace, boat construction and other fields. ${ }^{6-10}$ Carbon fiber $\left(\mathrm{C}_{\mathrm{f}}\right)$ is widely used as a reinforcing phase in matrix composite materials because of its high strength, high modulus, and low density, among other advantages. ${ }^{11-14}$ Therefore, the study of the performance at the interface between the PN resin and carbon fibers is a particularly important, although underappreciated, area of research.

Most research on interface performance has focused on the holistic and macroscopic performance of carbon fibers, for

\footnotetext{
${ }^{a}$ National Local Joint Engineering Laboratory for New Petro-chemical Materials and Fine Utilization of Resources, College of Chemistry and Chemical Engineering, Hunan Normal University, Changsha,410081, P. R. China. E-mail: sleeping1217@ 126.com

${ }^{b}$ College of Aerospace Science and Engineering, National University of Defense Technology, Changsha, 410073, P. R. China
}

example, in studies of the surface energy, ${ }^{13,15}$ contact angle, ${ }^{16,17}$ element constitution, ${ }^{17-19}$ and acidity of carbon fiber. ${ }^{20-23}$ These holistic carbon-fiber-performance factors certainly influence the interface performance of composites; however, the debonded and failure regions of carbon fibers are weak but critical components of understanding the performance of fiberreinforced composites. The properties and natures of these regions will be more important and meaningful than those of the carbon fibers alone. These interface regions exist at the micron scale, making in situ characterization significantly difficult, but with the help of Scanning Electron Microscopy combined with Energy Dispersive Spectrometry (SEM-EDS), in situ information from these micron-scale regions can be collected accurately. Using this advanced technology, the interface performance and adhesion mechanism of $\mathrm{C}_{\mathrm{f}} / \mathrm{PN}$ composites were investigated in this study.

Through micro-droplet testing, the interface-bonding performance between two kinds of resins (PN resin and epoxy resin) and carbon fiber were compared. The test results show that the interfacial shear strength of the $\mathrm{C}_{\mathrm{f}} / \mathrm{PN}$ composite is higher than that of the $\mathrm{C}_{\mathrm{f}}$ /epoxy resin composite. This is a very significant result for high-performance $\mathrm{PN}$ resin. To understand this result, we examined the interface morphology of the debonded surface of carbon fiber with SEM, and the residual cured resin could be clearly seen. Then, using the combined 
SEM-EDS method, the in situ elements of the de-bonded interface of carbon fiber could be detected. As a result, it is found that an increase in nitrogen in de-bonded interfaces is synchronous with an increase in interfacial shear strength. This interesting discovery prompted us to perform an in-depth analysis of the molecular structure of a PN polymer derived from $\mathrm{PN}$ resin using infrared spectroscopy. This polymer is a polyheterocycle containing $\mathrm{N}$, which is different from all other common polymers cured from resins. It is this distinctive polyheterocyclic structure that promotes the formation of interface conjugation between the PN polymer and graphene on the carbon-fiber surface. In addition, the ability of $\mathrm{N}$ to pull electrons is stronger than that of $\mathrm{C}$, which can further strengthen the conjugate forces between them. This novel interface adhesion mechanism explains the good interfacial bonding performance observed for the $\mathrm{C}_{\mathrm{f}} / \mathrm{PN}$ composite and also suggests that the nitrogen-containing heterocyclic structure of PN polymers have promising applications in the field of interfacial modification.

\section{Experimental}

\subsection{Materials}

High strength carbon fibers (T700 grade) were purchased from Dongli Corporation, with a tensile strength of $4.9 \mathrm{GPa}$, tensile modulus of $230 \mathrm{GPa}$ and an elongation at break of $2.1 \%$. The fiber of this manufacturer is PAN (polyacrylonitrile) based carbon fiber. The fiber is surface treated before leaving the factory. The treatment includes two steps, first anodic electrolytic oxidation to increase surface activity, and then sizing treatment to protect the active surface and prevent burrs to facilitate further use. The PN resin was supplied by the Hunan Normal University laboratory. The major components were 4-(4aminophenoxy)-phthalonitrile and poly-(arylene ether nitrile), among other aromatic nitrile compounds. Epoxy resin-51 was purchased from SINOPEC Baling Company. The curing agent for the epoxy resin was $4,4^{\prime}$-methylenebis(2-ethylbenzenamine) (DDM).

\subsection{Interfacial shear strength (IFSS) of the micro-composite}

The carbon fibers are sized before leaving the factory and the sizing agent is dilute solution of epoxy resin. This sizing agent can be well removed by acetone and Soxhlet extraction. The specific steps are as follows.

First, the carbon fiber was wound on a stainless steel cycle with a diameter of $3 \mathrm{~cm}$, then placed in a Soxhlet extractor, and an appropriate amount of acetone was added, and heated to $60{ }^{\circ} \mathrm{C}$ to maintain the siphon 5-6 times per hour. After extraction for 10 hours, the acetone solution turned yellow, then stopped heating and taken out the cycle. The cycle with fiber was placed in a vacuum oven at $-0.1 \mathrm{MPa}$ and $80^{\circ} \mathrm{C}$ for 2 hours. The desized and sized surfaces of the carbon fibers were observed by SEM. It was found that the resin particles on the surface of the fiber are removed, and the uneven oxidized surface is exposed (Fig. 1).
The micro-composite preparation and IFSS tests performed were similar to those previously reported in the literature. ${ }^{\mathbf{1 6}}$ The IFSS of micro-composites were tested by micro-droplet testing. The matrix resin was wetted onto a carbon fiber filament to form a micro-droplet that surrounded the fiber diameter due to the function of surface tension. The microdroplet resin was then cured in an oven. After resin curing, the single fiber was fixed in a concave mold. The knives came in contact with the solid resin droplet and the force required to debond the droplet from the fiber was recorded. The embedded length of each micro-droplet was measured through optical microscopic observation. The IFSS instrument (Model HM410, made in Japan) was used at the sensitivity of $1 /$ $100 \mathrm{gf}$ with a moving speed of $0.03 \mathrm{~mm} \mathrm{~min}^{-1}$. According to the maximum tension of a single fiber, we selected for droplets with diameters that were suitable for the test. The microdroplet resin was cured in an oven according to curing procedure in Table 1 . The PN polymers 1, 2 and 3, are derived from the polymerization of $\mathrm{PN}$ resin, but the post-cure temperature is different. The different post-cure temperatures result in somewhat different degrees of cure crosslinking.

The IFSS was calculated by the equation,

$$
\tau=F / \pi d l
$$

where $F$ is the maximum load required to debond the droplet from the fiber, $d$ is the fiber diameter and $l$ is the embedded length of the droplet. At least 20 valid data were collected for each system.

\subsection{Microtopography and elemental analysis of the de- bonded surface of micro-composites}

The morphological changes on desized and de-bonded surfaces of carbon fibers were examined by SEM. Simultaneously, the elemental composition of the corresponding micro-area were probed by SEM-EDS (FEI Quanta-20).

\subsection{Thermal stabilities of different cured polymers}

According to the curing procedure in Table 1, the cured polymers were prepared by thermo-gravimetric-analysis (TGA, Mettler-Toledo TGA/DSC1 STAR System) in a chamber under nitrogen atmosphere at a flow rate of $100 \mathrm{~mL} \mathrm{~min}^{-1}$.
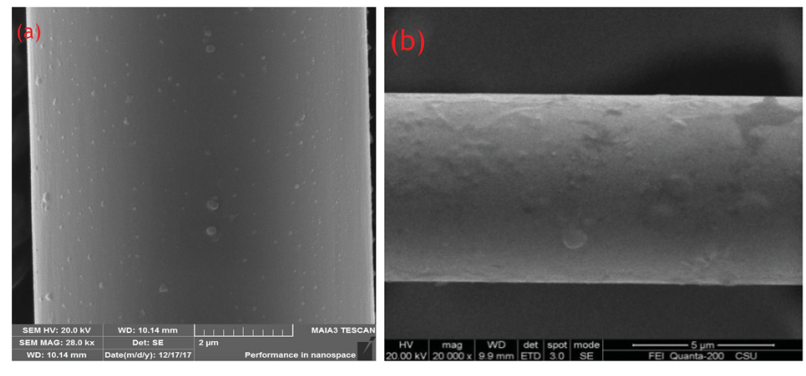

Fig. 1 The surfaces of sized fiber and desized fiber. (a) Sized; (b) desized. 
Table 1 Curing procedure for different resins

Cured polymer label

Epoxy polymer

PN polymer-1

PN polymer-2

PN polymer-3
Curing procedure

$95{ }^{\circ} \mathrm{C}, 1 \mathrm{~h}+135{ }^{\circ} \mathrm{C}, 2 \mathrm{~h}+170{ }^{\circ} \mathrm{C}, 2 \mathrm{~h}$
$2{ }^{\circ} \mathrm{C} \min ^{-1}$ from $30{ }^{\circ} \mathrm{C}$ to $320^{\circ} \mathrm{C}+320^{\circ} \mathrm{C}, 15$ min
$2{ }^{\circ} \mathrm{C} \min ^{-1}$ from $30{ }^{\circ} \mathrm{C}$ to $350{ }^{\circ} \mathrm{C}+350{ }^{\circ} \mathrm{C}, 15$ min
$2{ }^{\circ} \mathrm{C} \min ^{-1}$ from $30{ }^{\circ} \mathrm{C}$ to $380^{\circ} \mathrm{C}+380{ }^{\circ} \mathrm{C}, 15$ min
Thermal stabilities of the cured polymers were also evaluated by TGA at a heating rate of $20{ }^{\circ} \mathrm{C} \mathrm{min}^{-1}$ under nitrogen atmo-

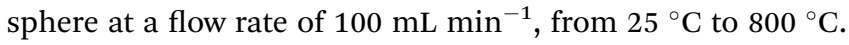

\subsection{Chemical structure of polymers}

The structure of the polymers derived from PN resin that had been treated under different curing procedures were examined by Fourier transform infrared spectra (FTIR) using a PerkinElmer Spectrum TWO spectrometer. FTIR spectra were recorded in infrared reflectance mode.

\section{Results and discussion}

\subsection{Interfacial shear strength}

In order to reduce the errors from testing and sample variations, more than 20 droplets with diameters agreeing with the test requirements are selected and studied. The IFSS distributions of different resins and curing temperatures are shown in Fig. 2. These distributions show classic bell curves that appear frequently in statistics, indicating that all the IFSS values agreed with a normal distribution.

The IFSS values of the polymers derived from different resins and curing procedures are listed in Table 2. Since epoxy resin is widely used in the preparation of composites, they are often used as reference for comparison in various literatures. $^{\text {24-26 }}$ The results show that the IFSS of the $\mathrm{C}_{\mathrm{f}} / \mathrm{PN}$ composite is higher than that of the epoxy micro-composite. This is a very significant result for the high performance PN resin. Furthermore, a gradually-increasing IFSS of the PN composite appeared along with a raise in curing temperature. This indicates that the interfacial adhesion strength of the $\mathrm{C}_{\mathrm{f}} /$ $\mathrm{PN}$ composite is stronger than that of the $\mathrm{C}_{\mathrm{f}}$ /epoxy composite. Moreover, the adhesion strength could be improved by increasing the temperature.

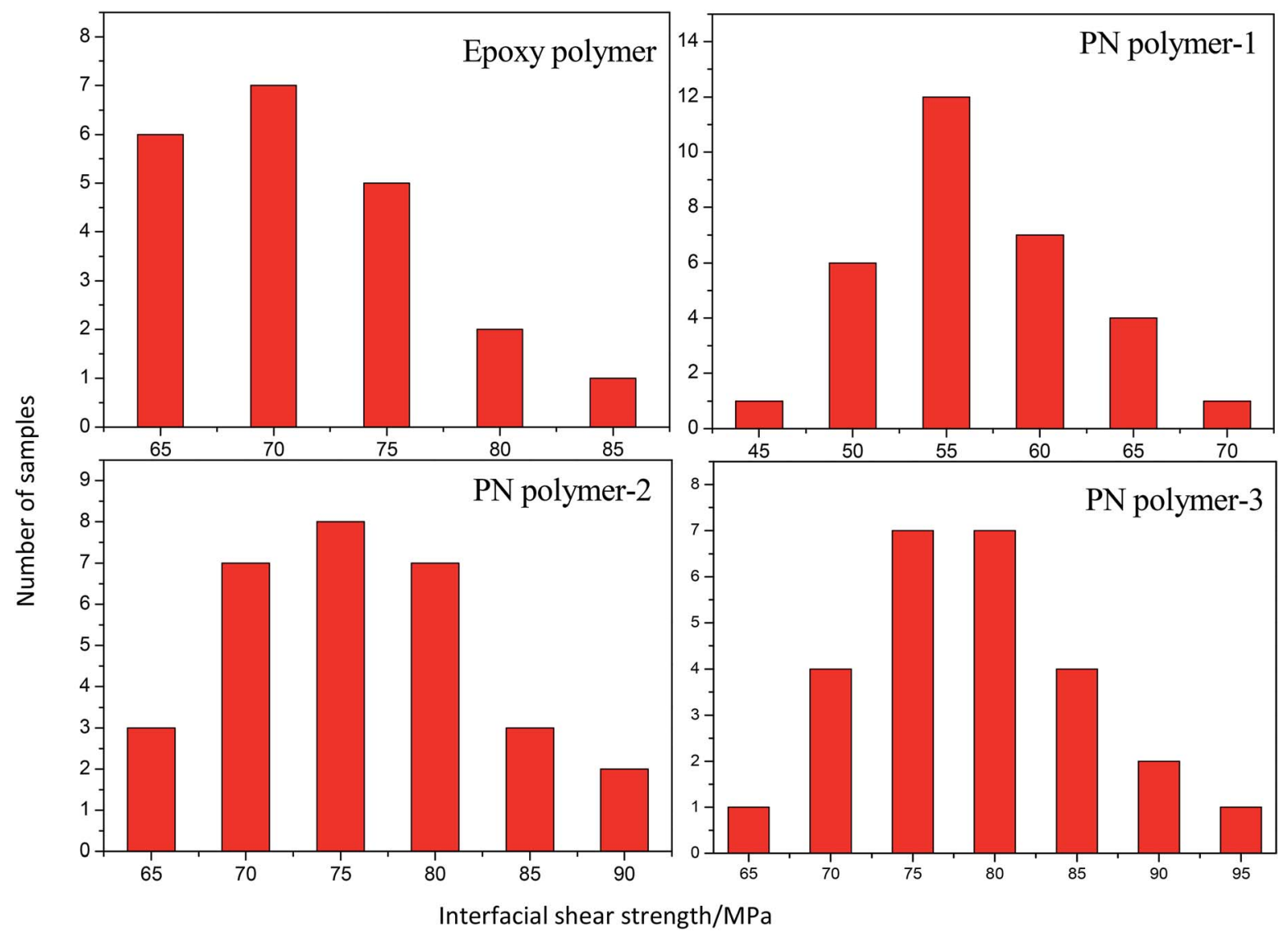

Fig. 2 IFSS distribution of epoxy and PN composites cured under different curing temperatures. 
Table 2 The IFSS of polymers derived from different resins and different cure procedures

\begin{tabular}{lllr}
\hline Cured polymer label & $\begin{array}{l}\text { Average of } \\
\text { IFSS/MPa }\end{array}$ & $\begin{array}{l}\text { Average deviation } \\
\text { of IFSS/MPa }\end{array}$ & $\begin{array}{l}\text { Relative average } \\
\text { deviation of IFSS/\% }\end{array}$ \\
\hline PN polymer-1 & 56.726 & 5.863 & $10.168 \%$ \\
PN polymer-2 & 75.173 & 7.103 & $9.449 \%$ \\
PN polymer-3 & 77.721 & 7.487 & $9.634 \%$ \\
Epoxy polymer & 70.870 & 6.254 & $8.824 \%$
\end{tabular}

\subsection{Micromorphology of interface}

To determine the cause of the micro-droplet test results, the desized and de-bonded surfaces of carbon fiber in microcomposites were observed and compared (Fig. 3). These images show that the desized carbon fiber surfaces are covered in bumps and rugged areas and the de-bonded surfaces of $\mathrm{C}_{\mathrm{f}}$ are smoother and more rounded than that of the desized fiber. This may be due to the fiber is surface treated through anodic electrolytic oxidation before sizing treatment.

In Fig. 3(b)-(d), it shows a layer of cured resin film remaining on the de-bonded carbon fiber surface, as the red coiled part in the picture. However, the resin residues are not easy to observe. This is mainly due to the cured PN resin residues are in the form of sheet-like and are in close contact with the surface of the fiber.
As is well known, carbon fiber is normally subjected to an anodic electrolytic surface treatment after it is manufactured. The edges of the basal planes can be activated and oxidized to introduce a range of oxygen-containing functional groups, such as carboxylic acid and phenolic hydroxyl groups. ${ }^{11,27-33}$ These oxygen-containing groups can react with the epoxy resin, as shown in Fig. 4, and promote the formation of a coating layer on the carbon fiber surface. As a result, the rugged and bumped surfaces become smoother and more rounded. Therefore, the interface adhesion performance of the $\mathrm{C}_{\mathrm{f}} /$ epoxy resin composite is enhanced. ${ }^{19,27}$

However, the carboxylic acid and phenolic hydroxyl groups on the $\mathrm{C}_{\mathrm{f}}$ surface can also react with $\mathrm{CN}$ groups in the PN resin (Fig. 5). ${ }^{34,35}$ Furthermore, the amino groups in the PN resin can react with carboxylic acid groups on the $\mathrm{C}_{\mathrm{f}}$. Therefore, the
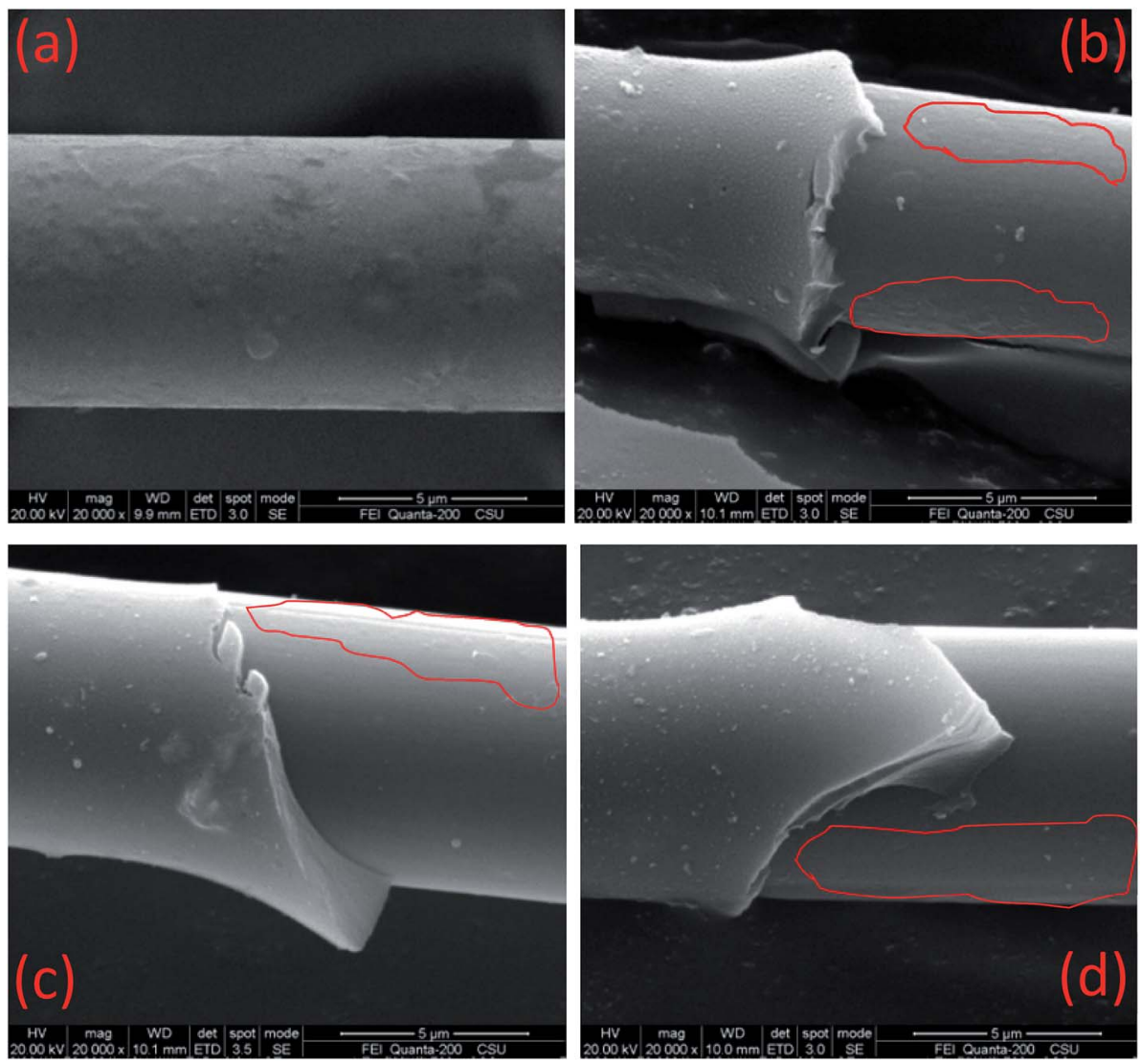

Fig. 3 Desized and de-bonded surfaces of carbon fiber in micro-composites (a) desized carbon fiber, (b) de-bonded surface of carbon fiber in an epoxy micro-composite, (c) and (d) de-bonded surfaces of carbon fiber in PN micro-composites at cure temperatures of $350{ }^{\circ} \mathrm{C}$ and $380{ }^{\circ} \mathrm{C}$, respectively. 

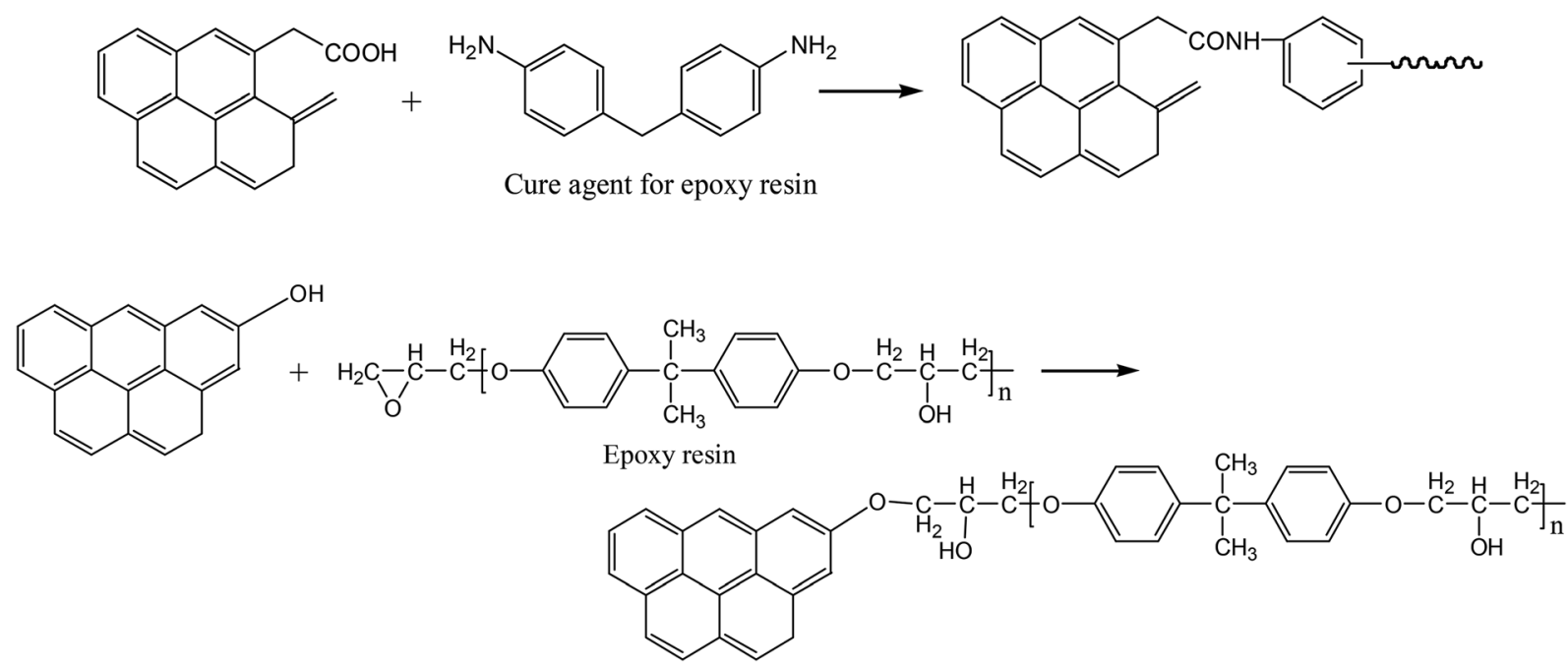

Fig. 4 Schematic of the reactions between epoxy resin and oxygen-containing functional groups on carbon fiber.

interface performance of the $\mathrm{C}_{\mathrm{f}} / \mathrm{PN}$ composites should be better than that of the $\mathrm{C}_{\mathrm{f}}$ /epoxy resin. This should be one of the reasons for the excellence interface adhesion performance of $\mathrm{C}_{\mathrm{f}} /$ PN composites.

\subsection{Elemental analysis}

In order to obtain in situ information on the de-bonded surface of carbon fiber in the PN micro-composite, a combined detection technology (SEM-EDS) was employed. The micromorphology images and energy spectra were recorded. From the spectra, the elemental composition of different samples are collected (Table 3 ).

Comparing the elemental composition of desized $\mathrm{C}_{\mathrm{f}}$ surfaces, there is a distinct increase in overall $\mathrm{N}$ and $\mathrm{O}$ content in the de-bonded $\mathrm{C}_{\mathrm{f}}$ surface for the $\mathrm{PN}$ micro-composites, regardless of the cure temperature. This suggests that there must be more residual $\mathrm{N}$ and $\mathrm{O}$ on the surface of $\mathrm{C}_{\mathrm{f}}$ in $\mathrm{PN}$ composites in general. When comparing the $\mathrm{N}$ content on debonded surfaces of $\mathrm{C}_{\mathrm{f}}$ in $\mathrm{PN}$ micro-composites prepared under different temperatures, a slight increase in $\mathrm{N}$ content is observed with the increase in cure temperature. When comparing the IFSS value in Table 2 to the $\mathrm{N}$ content in Table 3 , we find that there is a synchronous relationship between $\mathrm{N}$ content increase and IFSS improvement. This demonstrates that an increasing $\mathrm{N}$ content on the de-bonded surface of $\mathrm{C}_{\mathrm{f}}$ can help enhance the interface performance in $\mathrm{PN}$ composites.

\subsection{IR spectral analysis}

To determine the cause of the synchronous relationship between $\mathrm{N}$ content on the de-bonded surfaces of $\mathrm{C}_{\mathrm{f}}$ in $\mathrm{PN}$ microcomposites and IFSS improvement, the structures of cured polymers derived from PN resin were examined by FTIR.

As shown in Fig. 6, when the cure temperature increased, there is a decline in transmittance percentage at $2230 \mathrm{~cm}^{-1}$, which corresponds to a $\mathrm{CN}$ group. At the same time, an increase is observed at $1653 \mathrm{~cm}^{-1}, 1513 \mathrm{~cm}^{-1}$ and $1018 \mathrm{~cm}^{-1}$, corresponding to isoindole, triazine, and phthalocyanine, respectively. ${ }^{36-38}$ This suggests that the main products of the crosslinking reaction of $\mathrm{CN}$ are isoindole, triazine, and phthalocyanine. It also indicates that the higher cure temperature results in a higher conversion of the cross-linking reaction of $\mathrm{CN}$. This result is mainly due to the slow and sluggish reactivity of $\mathrm{CN}$,

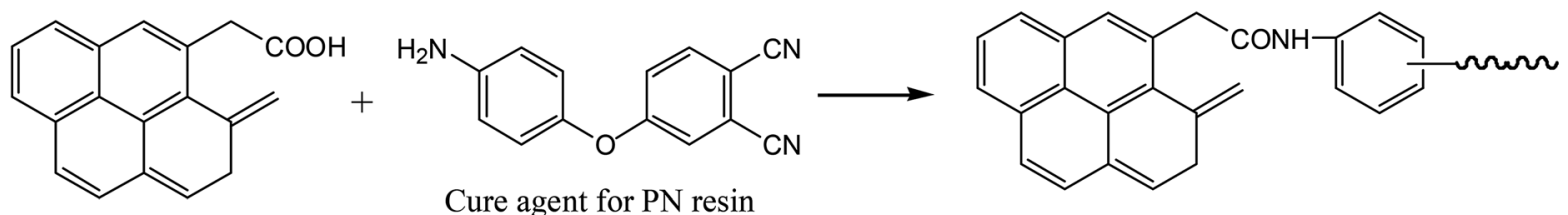

Cure agent for PN resin

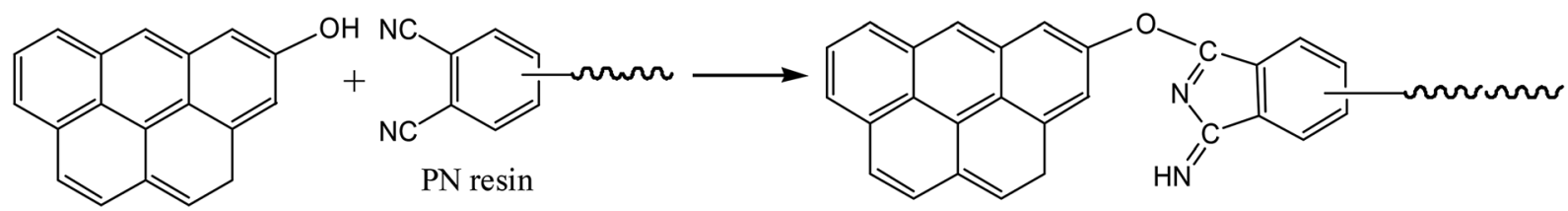

Fig. 5 Schematic of the reactions between PN resin and oxygen-containing functional groups on carbon fiber. 
Table 3 Elemental composition of desized $C_{f}$ and de-bonded surfaces of $C_{f}$ in a PN micro-composite derived from their energy spectrum diagrams with the aid of SEM
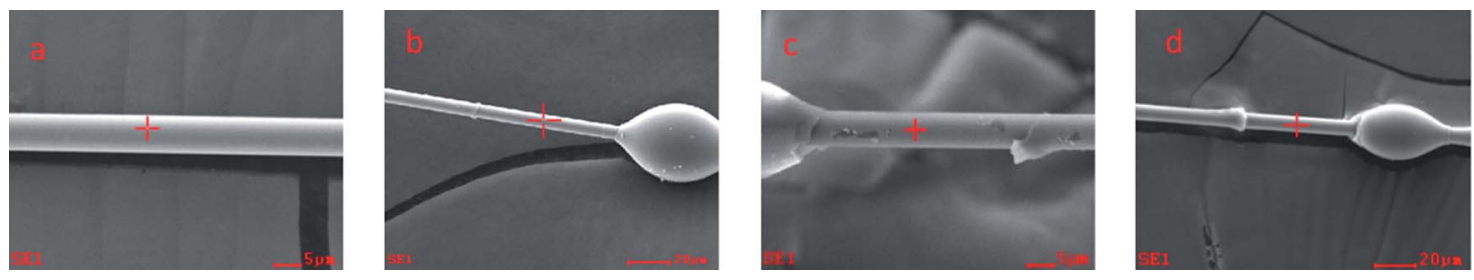

\section{$A_{\mathrm{t}} \%$ (debond surface of $\mathrm{C}_{\mathrm{f}}$ in PN micro-composites)}

\begin{tabular}{|c|c|c|c|c|}
\hline Element & $\begin{array}{l}A_{\mathrm{t}} \% \\
\left(\mathrm{a}, \text { desized surface of } \mathrm{C}_{\mathrm{f}}\right)\end{array}$ & $\mathrm{b}$, cure temperature is $320^{\circ} \mathrm{C}$ & $\begin{array}{l}\text { c, cure temperature } \\
\text { is } 350{ }^{\circ} \mathrm{C}\end{array}$ & $\begin{array}{l}\mathrm{d} \text {, cure temperature } \\
\text { is } 380^{\circ} \mathrm{C}\end{array}$ \\
\hline $\mathrm{C}$ & 94.53 & 93.92 & 93.82 & 93.84 \\
\hline $\mathrm{O}$ & 1.09 & 1.41 & 1.36 & 1.28 \\
\hline
\end{tabular}

which usually requires high temperatures and long reaction times before gelling occurs. ${ }^{\mathbf{1 0}, 39-41}$

All these cross-linking products derived from the additionpolymerization reaction, have conjugated structures (Fig. 7). These cyclic conjugated structures are different from those of the epoxy polymers. The epoxy polymers are composed mainly of chained compounds derived from ring-opening reactions. The primary chemical structure of the carbon fiber surface is layered graphene, consisting of repeated and conjugated benzene rings. These conjugated structures of cross-linking products from the PN resin and graphene of carbon fiber can interact with each other through pi-pi stacking. As a result, interface conjugation can be formed, as shown in Fig. 8, which can enhance the interface adhesion in the PN composite. Because the electron withdrawing ability of $\mathrm{N}$ is stronger than that of $\mathrm{C}$, the interfacial conjugation force between either triazine, isoindole, or phthalocyanine and a benzene ring is stronger than that between two benzene rings. Therefore, a higher $\mathrm{N}$ content will strengthen the interfacial conjugation force. This may be the cause for the synchronous relationship between $\mathrm{N}$ content increase and IFSS improvement.

The interface adhesion mechanism within $\mathrm{C}_{\mathrm{f}} /$ epoxy composites is usually considered to be a combined contribution of the reactions of chemical functional groups (i.e., the reactions between oxygen-containing functional groups on the edges of basal planes of carbon fiber and the amine and epoxy groups in the epoxy resin) and a suitable molecular dimension of resin to micropores in the carbon fibers. ${ }^{27}$ Therefore, the interface conjugation in $\mathrm{C}_{\mathrm{f}} / \mathrm{PN}$ composites contains a novel and additional force, when compared to the interface adhesion mechanism in $\mathrm{C}_{\mathrm{f}} /$ epoxy composites. This additional interface conjugation may be another cause for the excellent IFSS of $\mathrm{C}_{\mathrm{f}} /$ PN composites. Compared to other $\mathrm{C}_{\mathrm{f}}$ reinforced resin matrix composites, the interface conjugation function of the $\mathrm{C}_{\mathrm{f}} / \mathrm{PN}$

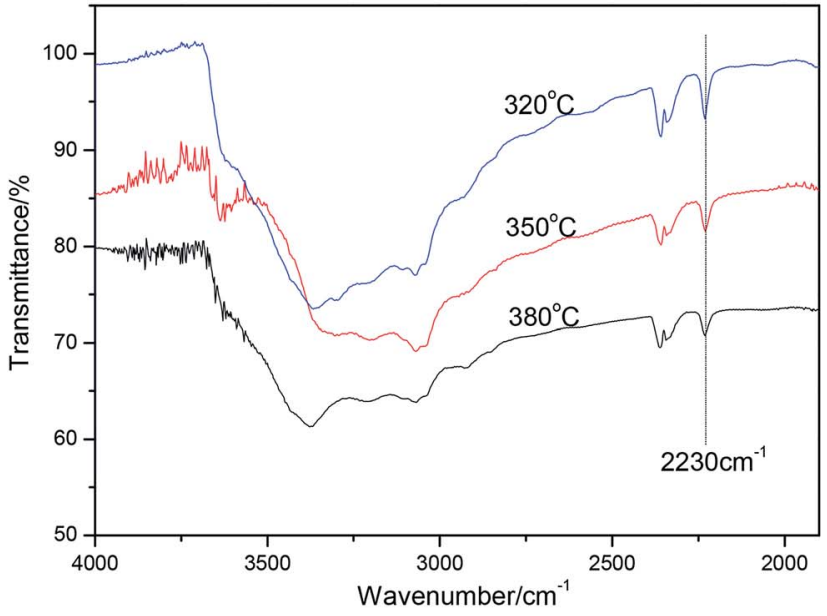

(a)

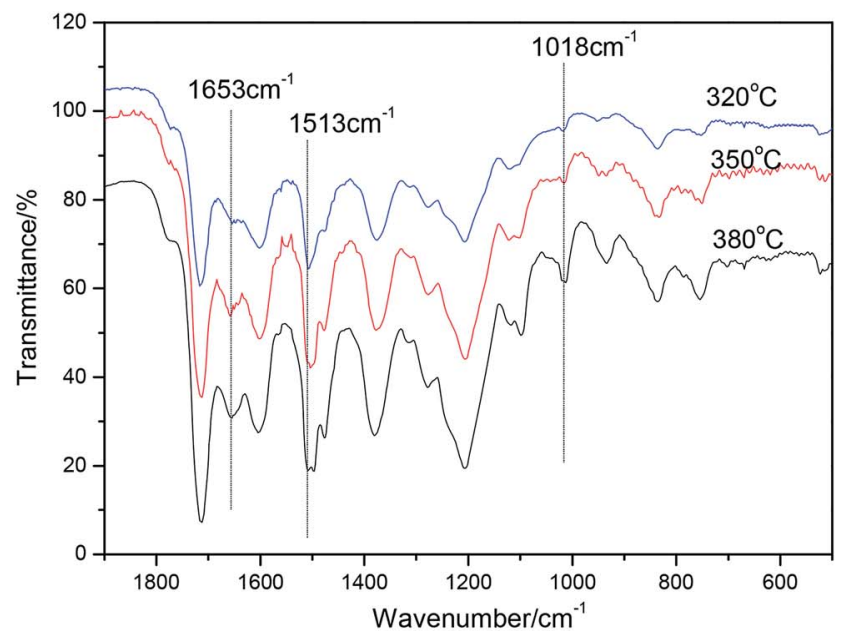

(b)

Fig. 6 IR spectrum of PN polymers cured under different temperatures. (a) Wavenumber from $1900-4000 \mathrm{~cm}^{-1}$, (b) Wavenumber from $500-$ $1900 \mathrm{~cm}^{-1}$ 


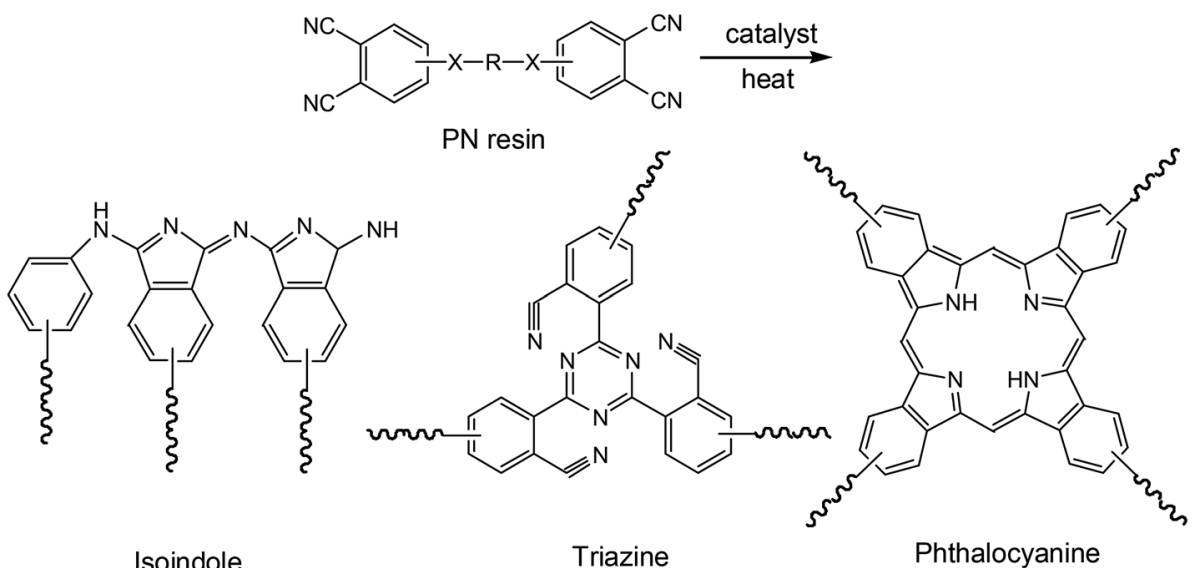

Fig. 7 The classical chemical structures of cross-linking reaction productions of PN resins.

composite is also a novel interfacial binding force that may allow PN resin to have more applications in the field of interfacial modification.

\subsection{Thermal stability}

The thermal stabilities of PN polymers prepared under different cure temperatures were detected by TGA. Their TGA curves are compared in Fig. 9. As expected, the initial decomposition temperature $\left(T_{5 \%}\right)$ and char yield at $800{ }^{\circ} \mathrm{C}$ of the $\mathrm{PN}$ polymers are elevated at increasing cure temperatures. This is completely consistent with the conclusions inferred from the IR results. The IR spectra suggest that higher cure temperatures lead to higher yields of triazine, isoindole, and phthalocyanine. As is well known, these compounds have outstanding thermal stabilities. Thus, it can be seen that the $T_{5 \%}$ and char yield at $800{ }^{\circ} \mathrm{C}$ kept rising with the cure temperature (Fig. 9).

As can be seen in Table 4, the initial decomposition temperatures of the PN polymers are between $441^{\circ} \mathrm{C}$ and $474{ }^{\circ} \mathrm{C}$, which are higher than most of the sizing resins, like epoxy, ${ }^{42}$ bismaleimides, ${ }^{43}$ polyurethane, ${ }^{44}$ and even some polyimides. ${ }^{44}$ Furthermore, the improvement in thermal stability (Table 4) is in step with the promotion of IFSS (Table 2). These results all suggest that PN resins not only have significant advantages in the field of interfacial modification, but also have excellent thermal stabilities. Thus, in the field of high temperature interface modification, PN resin will likely be more advantageous than other resins.

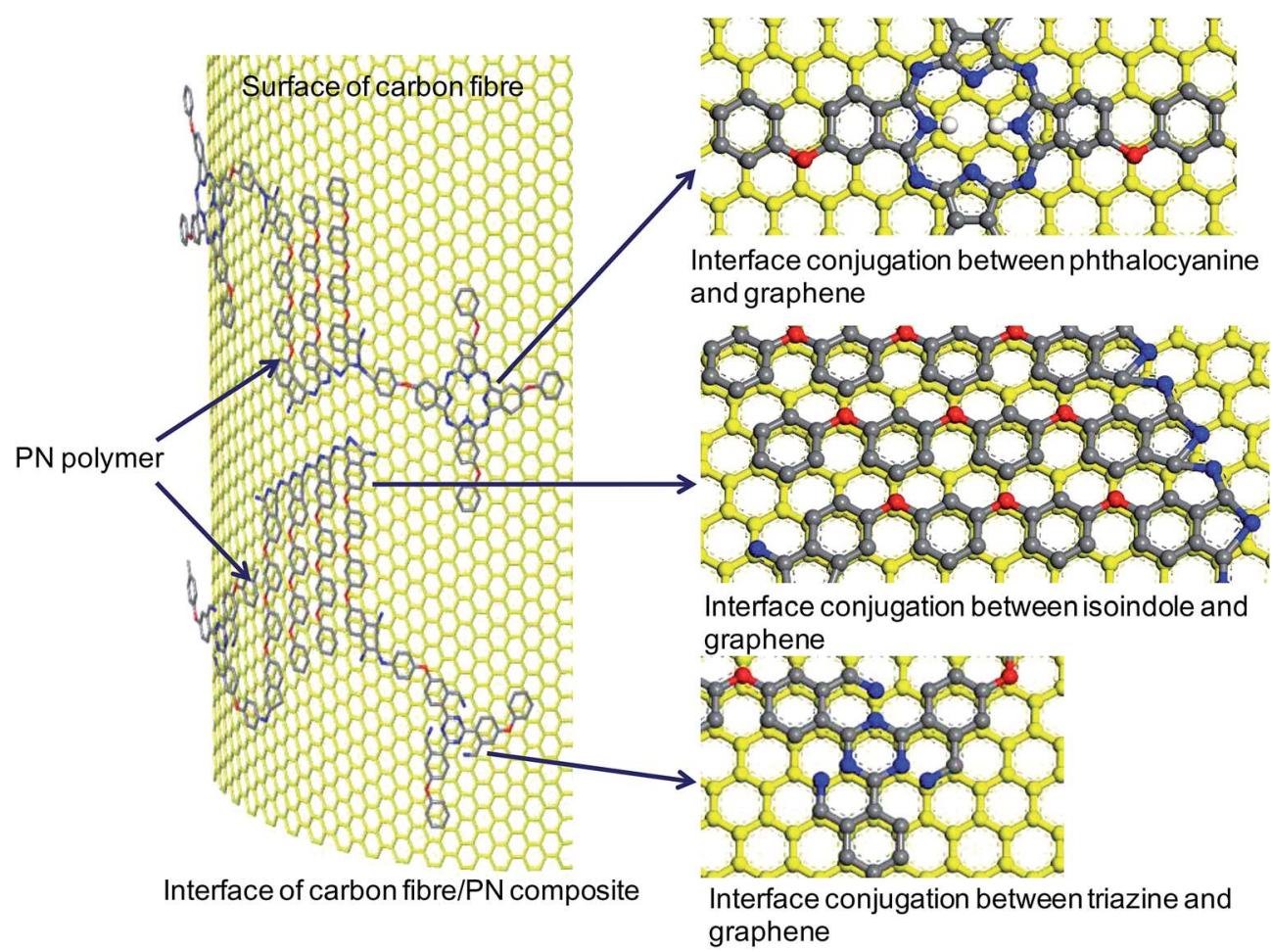

Fig. 8 Schematic diagram of interface conjugation between a PN polymer and the surface of carbon fiber (yellow = carbon fiber surface; gray = carbon atom; blue $=$ nitrogen atom; red $=$ oxygen atom). 


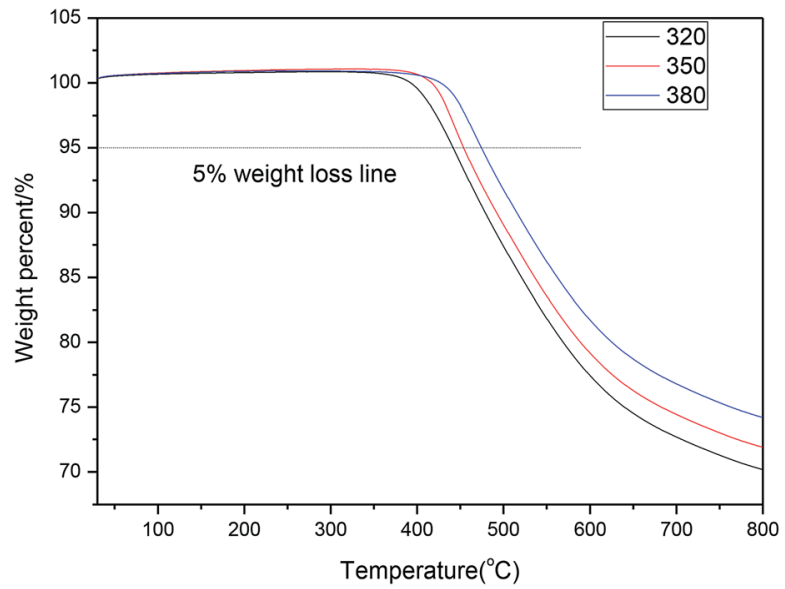

Fig. 9 TGA curves of PN polymers.

Table 4 Thermal stability of PN polymers

\begin{tabular}{llll}
\hline Label & & & \\
\hline PN polymer-1 & 441.5 & $T_{5 \%} /{ }^{\circ} \mathrm{C}$ & $\begin{array}{l}\text { Char yield } \\
\text { at } 800\end{array}$ \\
PN polymer-2 & 453.9 & 478.7 & 70.2 \\
PN polymer-3 & 474.5 & 492.1 & 71.9 \\
& & 515.4 & 74.2
\end{tabular}

\section{Conclusions}

To explore the interfacial performance of PN composites, microcomposites of $\mathrm{C}_{\mathrm{f}} / \mathrm{PN}$ and $\mathrm{C}_{\mathrm{f}}$ /epoxy resin were prepared. Their IFSSs were examined by micro-droplet testing. By comparing their IFSSs, the $\mathrm{C}_{\mathrm{f}} / \mathrm{PN}$ composite shows an obvious advantage. This indicates that there should be a more effective interfacial adhesion in the $\mathrm{C}_{\mathrm{f}} / \mathrm{PN}$ composite. The SEM results demonstrate that there are a polymer films coating on the de-bonded surface of the carbon fiber. The in situ SEM-EDS results show that there are more $\mathrm{N}$ and $\mathrm{O}$ elements in the de-bonded area around the carbon fiber in the $\mathrm{C}_{\mathrm{f}} / \mathrm{PN}$ composite. The FTIR results show that conjugated compounds are produced when the PN resin is treated at high temperatures. The PN polymers with conjugated chemical structures can interact with the graphene on the surface of the carbon fiber through $\pi-\pi$ stacking. The interaction between them promotes the formation of interface conjugation between the cured PN resin and the carbon fiber. The interface conjugation force is a new and additional interface adhesion function, when comparing to the interface adhesion mechanism of $\mathrm{C}_{\mathrm{f}}$ /epoxy composites. Thus, this conjugation may be the primary cause for the stronger IFSS observed for the PN composite when compared to the epoxy composite. In addition, with the excellent thermal stability of the PN polymer indicated by the TGA results, the PN resin is likely to have an advantage over epoxy composites in its application to the field of hightemperature interface modification.

\section{Conflicts of interest}

There are no conflicts to declare.

\section{Acknowledgements}

This research was financially supported by the National Natural Science Foundation of China (51803055), Hunan Provincial Key Research and Development Program (2018GK2062), and National and Local Joint Engineering Laboratory Open Fund (KF201805). We thank LetPub (https://www.letpub.com) for its linguistic assistance during the preparation of this manuscript.

\section{References}

1 Y. Lin, G. Ehlert and H. A. Sodano, Adv. Funct. Mater., 2009, 19, 2654-2660.

2 M. Sharma, S. Gao, E. Mäder, H. Sharma, L. Y. Wei and J. Bijwe, Compos. Sci. Technol., 2014, 102, 35-50.

3 L. Liu, C. Jia, J. He, F. Zhao, D. Fan, L. Xing, M. Wang, F. Wang, Z. Jiang and Y. Huang, Compos. Sci. Technol., 2015, 121, 56-72.

4 K. Uetani, S. Ata, S. Tomonoh, T. Yamada, M. Yumura and K. Hata, Adv. Mater., 2014, 26, 5857-5862.

5 X. Zhang, X. Fan, C. Yan, H. Li, Y. Zhu, X. Li and L. Yu, ACS Appl. Mater. Interfaces, 2012, 4, 1543-1552.

6 M. Laskoski, M. B. Schear, A. Neal, D. D. Dominguez, H. L. Ricks-Laskoski, J. Hervey and T. M. Keller, Polymer, 2015, 67, 185-191.

7 L. Sheng, C. Yin and J. Xiao, RSC Adv., 2016, 6, 22204-22212.

8 F. Zhao, R. Liu, C. Kang, X. Yu, K. Naito, X. Qu and Q. Zhang, RSC Adv., 2014, 4, 8383-8390.

9 L. Zhang, M. Liu, S. Roy, E. K. Chu, K. Y. See and X. Hu, ACS Appl. Mater. Interfaces, 2016, 8, 7422-7430.

10 J. Hu, Y. Liu, Y. Jiao, S. Ji, R. Sun, P. Yuan, K. Zeng, X. Pu and G. Yang, RSC Adv., 2015, 5, 16199-16206.

11 L. Ma, L. Meng, G. Wu, Y. Wang, M. Zhao, C. Zhang and Y. Huang, Compos. Sci. Technol., 2015, 117, 289-297.

12 E. Totry, J. M. Molina-Aldareguia, C. Gonzalez and J. LLorca, Compos. Sci. Technol., 2010, 70, 970-980.

13 P. Ma, S. Mo, B. Tang and J. Kim, Carbon, 2010, 48, 18241834.

14 J. Gu, N. Li, L. Tian, Z. Lv and Q. Zhang, RSC Adv., 2015, 5, 36334-36339.

15 R. L. Zhang, Y. D. Huang, D. Su, L. Liu and Y. R. Tang, Mater. Des., 2012, 34, 649-654.

16 L. Yao, M. Li, Q. Wu, Z. Dai, Y. Gu, Y. Li and Z. Zhang, Appl. Surf. Sci., 2012, 263, 326-333.

17 Y. Ren, C. Wang and Y. Qiu, Appl. Surf. Sci., 2007, 253, 92839289.

18 C. C. Guo, Y. Zhao, D. Chen and M. S. Zhan, Mater. Res. Innovations, 2014, 18, S4-S997.

19 C. Kozlowski and P. M. A. Sherwood, Carbon, 1987, 25, 751760.

20 N. Dilsiz and J. P. Wightman, Colloids Surf., A, 2000, 164, 325-336.

21 P. Denison, F. R. Jones and J. F. Watts, J. Mater. Sci., 1985, 20, 4647-4656.

22 J. Schultz and L. Lavielle, Interfacial Properties of Carbon Fiber-Epoxy Matrix Composites, Ameri Chem. Soci., 1989, vol. 391, pp. 185-202. 
23 Y. Bai, Z. Wang and L. Feng, Mater. Des., 2010, 31, 16131616.

24 K. M. Beggs, L. Servinis, T. R. Gengenbach, M. G. Huson, B. L. Fox and L. C. Henderson, Compos. Sci. Technol., 2015, 118, 31-38.

25 Q. Wu, R. Zhao, Q. Liu, T. Jiao, J. Zhu and F. Wang, Mater. Des., 2018, 149, 15-24.

26 B. Jiang, T. Zhang, L. Zhao and Y. Huang, Compos. Sci. Technol., 2017, 140, 39-45.

27 F. R. Jones and J. Adhes, J. Adhes. Sci. Technol., 2010, 24, 171202.

28 J. Dong, C. Jia, M. Wang, X. Fang, H. Wei, H. Xie, T. Zhang, J. He, Z. Jiang and Y. Huang, Compos. Sci. Technol., 2017, 149, 75-80.

29 T. Wang and P. M. A. Sherwood, Chem. Mater., 1995, 7, 10201030.

30 T. Wang and P. M. A. Sherwood, Chem. Mater., 1995, 7, 10311040.

31 Y. Wang, F. Zhang and P. M. A. Sherwood, Chem. Mater., 2001, 13, 832-841.

32 Y. Wang, F. Zhang and P. M. A. Sherwood, Chem. Mater., 1999, 11, 2573-2583.
33 J. D. Schaefer, A. J. Rodriguez, M. E. Guzman, C. Lim and B. Minaie, Carbon, 2011, 49, 2750-2759.

34 D. Augustine, D. Mathew and C. P. R. Nair, Polym. Int., 2013, 62, 1068-1076.

35 K. Zeng, K. Zhou, S. Zhou, H. Hong, H. Zhou, Y. Wang, P. Miao and G. Yang, Eur. Polym. J., 2009, 45, 1328-1335.

36 P. J. Burchill, J. Polym. Sci., Polym. Chem. Ed., 1994, 32, 1-8.

37 T. M. Keller and T. R. Price, J. Macromol. Sci., Part A, 1982, 6, 931-937.

38 J. Yang, X. Yang, Y. Zou, Y. Zhan, R. Zhao and X. Liu, J. Appl. Polym. Sci., 2012, 126, 1129-1135.

39 T. Zhang, J. Wang, M. Derradji, N. Ramdani, H. Wang, Z. Lin and W. Liu, Thermochim. Acta, 2015, 602, 22-29.

40 P. Yuan, Y. Liu, K. Zeng and G. Yang, Des. Monomers Polym., 2015, 18, 343-349.

41 M. Laskoski, A. Neal, T. M. Keller, D. Dominguez, C. A. Klug and A. P. Saab, J. Polym. Sci., Polym. Chem. Ed., 2014, 52, 1662-1668.

42 X. Ma, T. Reng and J. Wang, China Text. Leader, 2017, 44-46. 43 C. Wang, Synthesis and Characterization of a Bismaleimide Heat-resistant Emulsion Sizing Agent for Carbon Fibers, PhD thesis, Jilin University, 2011.

44 J. Wang, Z. Li and Y. Jiang, Synth. Fiber China, 2017, 36-38. 